Saúde 



\section{Judicialização da saúde}

\section{e medicalização: uma análise das orientações do Conselho Nacional de Justiça}

Aline MARQUES, ${ }^{I}$ CARLOS ROCHA, ${ }^{I I}$

FELIPE ASENSI III e DIEGO MACHADO MONNERAT ${ }^{I V}$

\section{Introdução}

A

APROXIMAÇÃo entre os campos de saber é um dos principais desafios do mundo contemporâneo. $\mathrm{O}$ paradigma formalista do direito, assim como o paradigma intervencionista da saúde, tem recebido nos últimos 30 anos reconfigurações diversas. Mais propriamente, a aproximação entre campos tão sólidos e com pressupostos não necessariamente congruentes gera uma nova forma de concebê-los. De campos isolados, direito e saúde com frequência têm se revelado como complementares.

Exemplo disso é a judicialização da saúde, que tem se desenvolvido no Brasil em relação a medicamentos, tratamentos, exames etc. Com frequência, os profissionais do direito são chamados a efetivar o direito à saúde, e, ao fazê-lo, mobilizam saberes e práticas plurais e contraditórias. Exemplo disso é a questão da opção sexual, que tem sido concebida em diversas decisões judiciais sob o prisma da saúde e pelo que se tem chamado de "biodireito", análogo à biomedicina. Outro exemplo é a sobrevalorização do saber médico e farmacêutico na composição de Núcleos de Apoio Técnico nos tribunais. Nesse sentido, o reconhecimento do direito à saúde tem passado pela medicalização, o que revela a tensão da aproximação entre direito e saúde no Brasil.

A partir do prisma aqui estabelecido, este artigo irá abordar o tema da relação entre judicialização e medicalização a partir das contradições do processo de reconhecimento do direito à saúde no Brasil. O objetivo do artigo consiste em evidenciar os parâmetros decisórios que o Poder Judiciário tem constituído desde 2010 e em que medida podem reproduzir uma visão medicalizante que produz reflexos contraditórios. A pesquisa qualitativa foi desenvolvida com a análise documental das orientações do Conselho Nacional de Justiça (CNJ) (resoluções, enunciados administrativos, instruções normativas da presidência e recomendações), com foco especial no biodireito e na opção sexual.

$\mathrm{Na}$ próxima seção, será realizada uma discussão teórica sobre direito à 
saúde e medicalização, com foco especial no modo como esses campos se aproximaram ao longo do tempo a partir da judicialização da saúde. Na seção que segue, serão analisados os parâmetros decisórios constituídos para a efetivação judicial da saúde, especialmente com a análise documental das orientações do CNJ e com o que se denomina biodireito. Por fim, nas considerações finais, será discutida criticamente a relação entre direito e saúde e em que medida ela pode contribuir para uma visão medicalizada dos direitos.

\section{Direito a saúde e medicalização}

\section{Direito à saúde no Brasil}

Com o advento da Constituição de 1988 e as intensas reivindicações de uma pluralidade de grupos sociais e políticos no Brasil, a saúde foi alçada à categoria de direito fundamental. A universalização da saúde foi acompanhada de sua institucionalização normativa, o que possibilitou a cristalização de princípios, normas e diretrizes que seriam desenvolvidos nos anos seguintes, cuja expressão mais significativa foi a criação do Sistema Único de Saúde (SUS). Em seu artigo 196, a Constituição estabelece que a saúde é um "direito de todos e dever do Estado" (Brasil, 1988), o que evidencia a pretensão universalizante desse direito. Em decorrência disso, a saúde passa a ser caracterizada como um direito fundamental e dever do Estado.

Para possibilitar a universalização na prática, foi promulgada a Lei n.8080/90, que institui as regras e princípios que regem o Sistema Único de Saúde (SUS). O SUS reforça a política de saúde brasileira como um direito de todos de forma indistinta, ${ }^{1}$ que possui não somente regras formais de organização, mas também princípios que orientam o seu desenvolvimento, tais como integralidade, descentralização, participação etc.

Em seu desenvolvimento mais recente, não é difícil observar a influência das instituições jurídicas na gestão dos serviços, seja dos tribunais, seja do Ministério Público e, até mesmo, da Defensoria Pública. Em algumas localidades, as instituições jurídicas podem até se desenvolver como um espaço de diálogo, pois passam a possibilitar a comunicação entre os principais atores que compõem o processo de formulação, gestão e fiscalização das políticas públicas em saúde em um foro comum. ${ }^{2}$ Portanto, no cotidiano brasileiro da efetivação do direito à saúde, temos o protagonismo decisivo das instituições jurídicas e sociais que, com frequência, atuam em conjunto e produzem resultados e impactos significativos nas políticas públicas de saúde.

Porém, um desafio comum à atuação das instituições jurídicas na saúde é o desconhecimento técnico dos profissionais do direito nesse assunto. Adicione-se a isso uma tendência de reproduzirem uma visão medicalizada, que tem sido muito associada ao senso comum, do que significa acesso à saúde. Afinal, o direito sanitário não compõe o quadro de disciplinas obrigatórias na faculdade de direito e é superficialmente cobrado em concursos públicos. De outro lado, o SUS se traduz numa política pública com várias especificidades, que variam des- 
de os princípios e diretrizes até a incorporação tecnológica, o financiamento e os recursos humanos. Exemplo disso é o que se denomina como biodireito - uma aproximação medicalizada da ideia de que a saúde é ausência de doença -, o que pode enviesar o modo como os profissionais do direito lidam com demandas judiciais de saúde que têm a opção sexual como eixo transversal.

\section{Medicalização da saúde}

Nos últimos anos têm surgido estudos e intervenções políticas que interrogam a evolução recente da saúde e da medicina no que se refere ao avanço das ciências biomédicas na efetivação do direito à saúde (Loyola, 1984; Souza; Luz, 2009; Camargo Jr., 2013; Zorzanelli et al., 2014).

O termo "medicalização" surgiu no final da década de 1960 em referência à apropriação dos modos de vida do homem pela medicina, tornando-se um termo descritivo para indicar algo que "se tornou médico" (Gauzendi; Ortega, 2012. p. 22). A importância do conceito de medicalização pode ser demonstrada pelo alcance que o tema vem adquirindo em publicações nos campos das ciências sociais e humanas nas últimas décadas. Diferentes definições são apresentadas para conceituar medicalização, mas nem sempre são compatíveis entre si. Para Foucault (1998, p. 79), trata-se de uma consequência dos processos de transformação social da medicina moderna. Para Conrad (2007, p. 05) o que se entende por medicalização ganhou amplitude, indo desde um determinado quadro médico ao o que é tratado sob a óptica de intervenção médica. Também considera-se o processo de transformação de problemas não considerados "médicos", em problemas médicos, sob a forma de doenças (Camargo Jr., 2013, p. 844). Nessa definição, a medicalização passa a se distanciar do seu sentido original - de definir comportamentos fora dos padrões "normais" - para designar ações fora do campo médico (por exemplo, o ativismo na saúde). Isso resulta na expansão das entidades médicas e na generalização da medicalização com desdobramentos sociais nem sempre positivos do ponto de vista da saúde da população (Zorzanelli et al., 2014).

Um desses desdobramentos sociais pode ser apontado pela utilização do conceito de medicalização como "extensão dos limites da autoridade médica" (Zorzanelli et al., 2014, p.1860), podendo gerar reações sociais imprevisíveis, especialmente "ligadas às possibilidades de intervenção a serviço de interesses econômicos descompromissados com os propósitos éticos associados à lógica da saúde" (Camargo Jr., 2013, p.845). O uso do termo medicalização, então, pode oferecer diferentes interpretações. Porém, uma das armadilhas do seu uso está associada ao poder médico na produção da doença, que pode "patologizar" qualquer demanda dos serviços de saúde, tais como: prescrição de medicamentos para casos que não tratam necessariamente de doenças (por exemplo, os contraceptivos); uso de tecnologias médicas; e introdução de novos fármacos para a psicofarmacologia (para tratamento de comportamentos como timidez) (Zorzanelli et al., 2014). 
A relação capitalista da medicina impôs, de certa forma, o surgimento de objetos medicalizáveis, tais como a infância, os comportamentos mentais fora dos padrões considerados normais, a gestação, a masculinidade e o sobrepeso (ibidem). O homo medicus, conforme descrito em Nunes (2009), seria a descrição do homem que pauta a vida pelo imperativo da saúde, sendo essa utilizada como a expressão de uma nova concepção de responsabilidade individual, viabilizada pela crescente dependência em relação ao complexo médico-industrial.

A medicalização social pode ser considerada um processo sociocultural complexo que pode transformar as vivências e seus enfrentamentos em necessidades médicas (Tesser et al., 2010). O excesso de medicalização, por sua vez, pode conduzir ao aumento dos procedimentos e diagnósticos clínicos e terapêuticos desnecessários, concentrando e reverberando a hegemonia médica, produzindo dessa forma, o aumento do controle social e do "imperialismo sanitário" (Camargo Jr., 2013, p.844).

Apontamentos para uma análise política da medicalização direcionam para uma intervenção da medicina no corpo social, pelo estabelecimento de normas morais de conduta e prescrição e de comportamentos, tornando os indivíduos "dependentes dos saberes produzidos pelos agentes educativo-terapêuticos" (Gaudenzi; Ortega, 2012 , p. 22), fator produtor de dependência e controle social. Ivan Illich (1975) pode ser considerado um dos maiores críticos aos desdobramentos da medicalização para a sociedade, descrevendo a produção da cultura medicalizada em suas dimensões sociais e políticas, considerando as perversidades da sociedade industrial e das tecnologias médicas. A perda da autonomia das pessoas é um dos principais elementos apontados pelo autor, tornando-se dependentes do saber de especialistas para o cuidado de sua própria saúde (Zorzanelli et al., 2014).

A respeito da chamada "teoria das doenças" no imaginário do mundo medicalizado, seja sobre a indústria de medicamentos, seja na produção de tecnologias - ambos reduzindo a autonomia dos indivíduos em relação à sua própria vida -, as doenças são vistas como coisas, relacionadas a lesões, que devem ser investigadas nos limites do corpo físico e corrigidas especialmente mediante o consumo das tecnologias produzidas, aumentando as formas de poder e controle social centrada no especialista (Tesser, 2006).

Isso é materializado por meio das tecnologias e intervenções constantes da indústria farmacêutica, sendo forma de controle social pelo enfoque exclusivo na doença. Como consequência, é constituído um processo constante de transformação de problemas não médicos em problemas médicos sob a forma de doenças.

\section{O campo do biodiveito}

A evolução do capitalismo impôs novos problemas de natureza sanitária, agravando as desigualdades sociais, induzindo o surgimento ou aumento de problemas como desnutrição, violência, doenças infectocontagiosas, além dos 
problemas da população urbana trabalhadora, como depressão, ansiedade, entre outras (Souza; Luz, 2009). O desenvolvimento das tecnologias de diagnósticos conferiu materialidade às doenças e sua ciência, e o surgimento do arsenal farmacológico respondeu às necessidades de combatê-las. Assim, as instituições médicas reproduzem hoje os saberes do campo, materializando as tecnologias e as mudanças científicas possibilitadas com o desenvolvimento da biotecnologia. Isso levou os profissionais das áreas da saúde a pensar sobre seu agir e a buscar soluções éticas para conduzir suas ações (Barboza, 2012).

Para nortear as ações desencadeadas pelo desenvolvimento biotecnológico, surgiu o campo da bioética, que apresenta como marco valorativo três princípios: autonomia, beneficência e justiça. O princípio da autonomia da pessoa representa a capacidade que tem a racionalidade humana de governar-se, ou seja, o princípio da escolha. A beneficência trata da relevância da pesquisa com redução de ônus para os sujeitos pesquisados. Por fim, o princípio da justiça afirma a distribuição justa, equitativa e universal dos benefícios dos conhecimentos (Myszczuk; Meirelles, 2008, p.335).

A este ponto, é importante diferenciar as ideias de bioética e biodireito. A bioética apresenta diferentes concepções, que se aplicam transversalmente, em especial entre medicina e biologia, ética e direito etc. Esse campo tem sido entendido a partir da ideia de ética da vida ou ética médica e, ainda mais atualmente, ética biomédica. Vale dizer que os princípios da norma bioética são de natureza moral. Ao contrário, as normas jurídicas se caracterizam por comandos normativamente estabelecidos pelo Estado.

O biodireito, por sua vez, pode ser considerado a disciplina do direito que trata das normas reguladoras da conduta humana em face dos avanços da biologia, da biotecnologia e da medicina. Os assuntos são variados, tais como a reprodução humana, os limites e processos da vida e da morte e a representação cultural do corpo ou da pessoa humana. Diante do processo de medicalização crescente, o biodireito surge para direcionar as decisões judiciais no que diz respeito às relações entre médicos, usuários e instituições de saúde, com foco nas responsabilidades legais. Os avanços da biomedicina afetam diretamente a vida das pessoas, do ponto de vista individual e coletivo, gerando tensões que são foco da intervenção do direito, ou melhor, do biodireito (Barboza, 2012).

Porém, observa-se uma contradição da visão de biodireito se relacionado com os grupos socialmente vulneráveis e com situações de repercussão social (preconceito, discriminação etc.). Trata-se de um paradoxo: por um lado, busca-se a inclusão de todos os indivíduos a partir da universalização, e, por outro, esvazia-se a "inclusão de todos", quando não é possível identificar as individualidades e as reais necessidades dos sujeitos de cuidado (Schiocchet, 2012).

Inserido num contexto de saúde, a sexualidade foi estabelecida como objeto de controle, por meio do saber e do poder, especialmente centrado nos especialistas detentores dos conhecimentos específicos. Na dinâmica judicial, isso 
pode se operar mediante o reforço à biomedicalização e do biopoder. Isso pode significar que os profissionais do direito podem atuar simultaneamente como agentes de aprofundamento do direito à saúde e, ao mesmo tempo, como agentes de reprodução da medicalização. Isso ganha especial relevo nas demandas judiciais de saúde que têm algum tipo de opção sexual como eixo transversal (adoção, mudança de nome, mudança de sexo, união civil etc.).

Diante da indefinição prática do biodireito, a partir da controvérsia gerada pelos paradoxos sociais, e da incompreensão da sua atuação social, somada à inexistência de regulamentação legal específica sobre o debate da sexualidade, há que avançar criticamente sobre se o biodireito auxilia a efetivação do direito à saúde.

\section{Resultados}

Nos últimos anos, o Judiciário buscou se debruçar de forma mais sistemática sobre o ato de julgar em saúde e tem buscado fazer que esse ato não seja necessariamente uma decisão solitária. O crescimento da importância e do protagonismo judicial em matéria de saúde trouxe a necessidade de se estabelecer uma ação mais coordenada e estratégica.

Não é por acaso que, desde 2010, o CNJ tem liderado e estimulado de maneira mais sistemática a atuação do Judiciário, buscando estabelecer uma política judiciária para a saúde. As estratégias oriundas dessas medidas envolvem desde a criação do Fórum Nacional do Judiciário para a saúde até Comitês Estaduais de Saúde e recomendações e enunciados sobre como os juízes podem decidir as demandas que thes são apresentadas. Desde então, em meio a avanços e desafios, o CNJ tem estimulado, discutido, desenvolvido e implementado diversas ações e estratégias que visam, em alguma medida, oferecer parâmetros e diretrizes para a atuação judicial em saúde.

A pesquisa qualitativa teve como base os anos 2010 a 2015, que correspondem ao lapso em que o CNJ dedicou-se a estabelecer uma política pública judiciária para a saúde e a criar parâmetros e diretrizes decisórias para o julgamento das ações em saúde. Os documentos analisados foram os enunciados, recomendações, resoluções e declarações do $\mathrm{CNJ}$ no período, e teve como foco as seguintes dimensões: a) concepção de saúde inerente aos documentos; b) medicalização do direito à saúde e da opção sexual, tendo como foco a ideia de biodireito. Boa parte dessas orientações, como será visto, está alicerçada na reprodução de uma visão medicalizante do tema, especialmente no que concerne às demandas que têm como eixo transversal a opção sexual.

\section{$O C N J$ e seu poder regulamentar}

Antes de esmiuçar mais detalhadamente os atos normativos do Conselho Nacional de Justiça, cabe aqui breve explicação sobre seu conceito e objeto, bem como de seus atos. Segundo o seu site, na seção "Quem somos", diz-se que "o Conselho Nacional de Justiça $(\mathrm{CNJ})$ é uma instituição pública que visa aperfeiçoar o trabalho do sistema judiciário brasileiro, principalmente no que diz respeito ao controle e à transparência administrativa e processual". 
Já sua competência é definida pelo parágrafo $4^{\circ}$ do artigo 103-B da Constituição Federal, artigo esse incluído pela Emenda Constitucional 45 de 2004, que diz "Compete ao Conselho o controle da atuação administrativa e financeira do Poder Judiciário e do cumprimento dos deveres funcionais dos juízes, cabendo-lhe, além de outras atribuições que lhe forem conferidas pelo Estatuto da Magistratura". Demonstra-se que o CNJ tem competência administrativa, tendo o papel de exercer controle administrativo e financeiro do Judiciário, bem como da atividade jurisdicional dos juízes, sendo o Conselho órgão judicial, em sentido lato, mas não órgão jurisdicional. A despeito das discussões acerca da natureza jurídica dos atos do CNJ, o Conselho Nacional de Justiça realiza sua função de controle por meio dos seus Atos Administrativos.

Esses podem ser divididos em quatro espécies, segundo o site do CNJ e o Regimento Interno do Conselho Nacional de Justiça, aprovado pela Resolução n.67, de 3 de março de 2009. Apesar de cada um desses atos ter seu âmbito de influência e controle, há certa gradação de importância, na ordem adiante apresentada, por sua especificidade, atributos e potencialidade normativa, essa garantida constitucionalmente. São eles:

- Resoluções: instrumentos regulatórios próprios de que se utiliza o CNJ, no cumprimento das leis, para exercitar seus atos e fatos de gestão.

- Enunciados Administrativos: exposições resumidas sobre assuntos já discutidos em Plenário.

- Instruções Normativas da Presidência: decisões tomadas pelo Presidente do Conselho sobre questões que dependem de resolução. São atos que determinam o comportamento para atender a determinada execução. Têm a função de agilizar o funcionamento interno do CNJ, a compreensão, a especificação de um ato ou ordem de hierarquia maior, por exemplo, uma resolução.

- Recomendações: atos que recomendam aos tribunais e magistrados a adoção de medidas para cumprir determinado objetivo.

Detalhe importante é que, com relação às Resoluções e Enunciados Administrativos, o parágrafo $5^{\circ}$ do artigo 102 do Regimento Interno afirma que essas "terão força vinculante, após sua publicação no Diário da Justiça e no sítio eletrônico do CNJ". Também deve-se ressaltar que a atuação regulamentar do CNJ se dá no âmbito de sua competência administrativa. O poder regulamentar "é um instrumento pelo qual a administração pública visa efetivar a aplicabilidade da lei, através da edição de atos gerais e complementares" (Castro; Santos, 2011, p.13), este que é diferente de poder legislativo, bem como atos regulamentares são diferentes de atos legislativos. Todavia,

[...] ao expedir atos regulamentares, a administração pública está exercendo função normativa, pois, assim como as leis, os atos expedidos possuem as características de abstratividade e impessoalidade, entretanto, seu fundamento é extraído diretamente da lei a qual está a complementar. (Castro; Santos, 2011, p.13) 
Desse modo, esclarecidos função e atos de controle do Conselho Nacional de Justiça, apresenta-se como esses influenciam o processo de judicialização da saúde e de medicalização.

\section{Recomendações do CNJ}

Em 2010, o CNJ publicou a Recomendação n.31. Considerando o volume processual de centenas de milhares de processos em saúde, essa recomendação teve como objetivo orientar os tribunais na adoção de medidas que subsidiem os magistrados para assegurar maior eficiência na solução das demandas judiciais envolvendo a assistência à saúde pública.

Nesse sentido, o CNJ estimulou que os tribunais, dentre outras medidas, celebrem convênios que objetivem disponibilizar apoio técnico composto por médicos e farmacêuticos para auxiliá-los na apreciação das questões clínicas apresentadas pelas partes, observadas as peculiaridades regionais. Além disso, dentre diversas medidas orientadas pela medicalização, o CNJ estabeleceu que os magistrados:

a) procurem instruir as ações, tanto quanto possível, com relatórios médicos, com descrição da doença, inclusive CID, contendo prescrição de medicamentos, com denominação genérica ou princípio ativo, produtos, órteses, próteses e insumos em geral, com posologia exata;

b) evitem autorizar o fornecimento de medicamentos ainda não registrados pela Anvisa, ou em fase experimental, ressalvadas as exceções expressamente previstas em lei;

c) ouçam, quando possível, preferencialmente por meio eletrônico, os gestores, antes da apreciação de medidas de urgência;

d) incluam a legislação relativa ao direito sanitário como matéria no programa de direito administrativo dos respectivos concursos para ingresso na carreira da magistratura, além de incorporar o direito sanitário nos programas dos cursos de formação, vitaliciamento e aperfeiçoamento de magistrados;

e) promovam visitas dos magistrados aos Conselhos Municipais e Estaduais de Saúde, bem como às unidades de saúde pública ou conveniadas ao SUS, dispensários de medicamentos e a hospitais habilitados em Oncologia como Unidade de Assistência de Alta Complexidade em Oncologia (Unacon) ou Centro de Assistência de Alta Complexidade em Oncologia (Cacon).

No mesmo ano, o CNJ ainda publicou a Resolução n.107, que instituiu o Fórum Nacional do Judiciário (FNJ) para monitoramento e resolução das demandas de assistência à saúde. Dentre as suas atribuições, o FNJ deve elaborar estudos e propor medidas concretas para o aperfeiçoamento, reforço e efetividade dos processos judiciais, além de refletir sobre a prevenção de novos conflitos em matéria de saúde. A Resolução ainda prevê a possibilidade de os tribunais realizarem termos de cooperação técnica com órgãos ou entidades públicas ou privadas para o cumprimento de suas atribuições. 
Em 2011, o CNJ ainda publicou a Recomendação n.36 que, inspirada na Recomendação n.31, trouxe regramentos específicos para o julgamento de demandas envolvendo a saúde suplementar. Desse modo, ao estabelecer a importância de se oficiar a Agência Nacional de Vigilância Sanitária (Anvisa) e a necessidade de incluir representantes das operadoras de planos de saúde nos Comitês Estaduais de Saúde, o CNJ deu mais um passo na coordenação de estratégias judiciais para o tema.

\section{Enunciados do CNJ}

Em 2014 e 2015, o CNJ realizou enunciados a partir da I e II Jornada de Direito da Saúde. Em diversos enunciados se observa a medicalização, especialmente nos enunciados de número 12, 15, 17, 18, 30 e 31 (Conselho Nacional de Justiça, 2014) e enunciados de número 48 e 51 (Conselho Nacional de Justiça, 2015) que serão analisados à frente.

Os enunciados situam como "profissionais de saúde" apenas médicos e farmacêuticos, (geralmente ${ }^{3}$ ) excluindo de suas recomendações e enunciados outros profissionais, como psicólogos, terapeutas ocupacionais, fisioterapeutas, assistentes sociais, dentre outros. Parte-se de uma concepção reduzida de saúde e, ao mesmo tempo, reproduz-se a medicalização, como veremos a seguir.

O enunciado n.12 (Conselho Nacional de Justiça, 2014) afirma que a "inefetividade do tratamento oferecido pelo SUS, no caso concreto, deve ser demonstrada por relatório médico". Os enunciados de número $17^{5}$ e $18^{6}$ reiteram os Núcleo de Assessoramento Técnico (NAT) e Núcleo de Apoio Técnico em Saúde (NATS) como instâncias às quais o magistrado deveria, sempre que possível, se dirigir. Isso corrobora o ponto de vista apresentado nas recomendações 31 e 36, explicadas no tópico anterior, pois verifica-se que apenas duas categorias (médicos e farmacêuticos) compõem o "apoio técnico" dos magistrados. $\mathrm{O}$ mesmo se observa no enunciado n. $31^{7}$ sobre saúde suplementar, que também sublinha a obtenção de informação por parte do juiz junto ao NAT ou Câmara Técnica, que deve ser composto somente por médicos e farmacêuticos.

No conteúdo do enunciado n. $15,{ }^{8}$ fica evidente a concepção de saúde como reduzida à prescrição médica, que também é reforçado pelas recomendações do CNJ. Trata-se de item que versa apenas sobre os parâmetros concernentes a esse tipo de prescrição. Nesses documentos, subentende-se que a saúde significa acesso a medicamentos, e, assim sendo, a prescrição medicamentosa é um item decisivo para o julgamento. Não são encontrados enunciados, recomendações ou resoluções que trabalhem com outra noção de saúde ou que insinuem a necessidade de outra visão para a compreensão do processo saúde-doença.

O enunciado $\mathrm{n} .30^{9}$ da saúde suplementar, por exemplo, afirma a necessidade de se "ouvir médico ou odontólogo assistente quando houver dúvida" quanto à prescrição. Novamente, a visão privilegiada é fortemente medicalizada.

Quanto ao enunciado n. $48^{10}$ (Conselho Nacional de Justiça, 2015), sustenta-se que as "altas de internação hospitalar de paciente, $[. .$.$] independem de$ 
novo pronunciamento judicial, prevalecendo o critério técnico profissional do médico", e não de equipe multi ou interdisciplinar de saúde. No mesmo sentido, o enunciado $\mathrm{n} .5 \mathrm{l}^{11}$ grifa a necessidade de "requerimento médico circunstanciado" para caracterização de situação de urgência/emergência. Esse enunciado situa o médico como o profissional que detém o saber-poder legitimado ante o Poder Judiciário para definir as situações de urgência/emergência.

Em contrapartida, da mesma forma que os enunciados são mostras de uma visão medicalizada dos processos de saúde-doença, os mesmos documentos também são interessantes sob o ponto de vista de sua ambiguidade. ${ }^{12}$ Apesar da tendência medicalizante, esses mesmos documentos possuem enunciados que desmedicalizam o mundo. Isso fica evidente com os enunciados de números 40, 42 e 43 (Conselho Nacional de Justiça, 2014). É interessante observar que esses enunciados, embora orientados por um propósito desmedicalizador, encontram-se intitulados como biodireito pelo Conselho Nacional de Justiça. Isso evidencia a sua ambiguidade conceitual e epistemológica.

O enunciado $\mathrm{n} .40^{13}$ afirma que é "admissível [...] a inclusão do nome de duas pessoas do mesmo sexo, como pais". Apesar de ser restrito ao caso de reprodução assistida, parece um avanço em uma direção menos medicalizada da existência, pois permite que duas pessoas, amparadas legalmente, que possuem o mesmo código cromossomial (XX ou XY) podem requerer seus nomes na certidão de seu filho/filha. Nada menos biomedicalizante, no sentido atribuído por Clarke et. al (2003), do que essa posição, por mais que tais discussões estejam longe de chegar ao consenso no que se refere à opinião pública em geral e às variadas instituições sociais - como Família, Igreja (em suas variadas vertentes, católica, evangélica e etc.), Câmara de Deputados, Senado, autarquias, Universidade, dentre outras. A posição assumida nesse documento do CNJ parece interessante ao se distanciar de uma expressão biomédica (de cunho potencialmente eugênico), que poderia advogar em favor de que somente casais heterossexuais tivessem o direito de passar seus nomes às gerações seguintes, por exemplo.

O enunciado $\mathrm{n} .42^{14}$ sustenta que "[q]uando comprovado o desejo de viver e ser aceito enquanto pessoa do sexo oposto, $[\ldots]$ a cirurgia de transgenitalização é dispensável para a retificação de nome no registro civil" (Conselho Nacional de Justiça, 2014). E, ainda, que "[é] possível a retificação do sexo jurídico sem a realização da cirurgia de transgenitalização" (enunciado n.43, Conselho Nacional de Justiça, 2014). Dessa forma, fica evidente o caráter desmedicalizante vigente no documento, pois o viés privilegiado é o "desejo de viver e ser aceito enquanto pessoa do sexo oposto" ou a concepção de que o "sexo jurídico" independe da transgenitalização. A visão medicalizada da existência - ou antes, uma visão eivada de concepções de mundo baseadas em um paradigma que representaria o imperialismo médico e sua função de controle social - não estaria aqui representada. Ao contrário, esses enunciados expressam uma visão de mundo que privilegia a concepção do próprio sujeito de direitos, 
como ele percebe a si mesmo e a seu corpo, em detrimento de uma concepção medicalizada de vida, de corpo ou condutas interpessoais.

Nos documentos do CNJ, observa-se uma definição implícita de saúde como "fornecimento de medicamentos, produtos ou tratamentos" (enunciado n.13, Conselho Nacional de Justiça, 2014). Nesse sentido, de maneira ambígua, os documentos analisados reafirmam essa concepção medicalizada e medicalizante dos processos de saúde-doença e, ainda, evidenciam a concepção de paciente-cidadão-consumidor como fundamento desse reducionismo. Ao mesmo tempo que ampliam a efetivação da saúde, reforçam a sua medicalização mediante o saber médico e farmacêutico ou, ainda, ao enquadrarem a opção sexual e os direitos de reconhecimento à luz do biodireito.

\section{Discussão}

Os resultados da pesquisa permitem a discussão sobre como a medicalização pode produzir efeitos diversos no cotidiano decisório do Judiciário, inclusive no que concerne à produção ambígua e contraditória do que significa o direito à saúde. Isso tem repercussões até na questão da opção sexual, especialmente quando se enquadra o tema como inserido no campo do biodireito.

Por exemplo, como visto, o enunciado de n.12 tem conteúdo predominantemente medicalizado, pois a "inefetividade do tratamento" só poderia ser "demonstrada por relatório médico". Esse dispositivo de saber-poder é legitimado perante outra cadeia de argumentos: a cadeia de argumentos jurídicos e as práticas a elas atreladas. Nos documentos o saber-poder legítimo situado como orientador das práticas jurídicas no Brasil é a biomedicina, representada pelos médicos e farmacêuticos. A biomedicina situa-se como locus de estabelecimento de balizas "éticas, sanitárias, farmacológicas". É à biomedicina, e a seu corpus teórico-prático, que os documentos do $\mathrm{CNJ}$ se referem para qualificar o que é ético, sanitário ou farmacológico. Inclusive, a definição do que pode ser considerado "tratamento e periodicidade, medicamentos e doses", também, será definido a partir do saber-poder biomédico.

Vale ressaltar, porém que, nos documentos, a biomedicina não necessariamente é usada de maneira onipotente, tendo em vista a importância que aqueles conferem às agências reguladoras, em especial à Anvisa. A validade da prescrição médica está submetida à existência de previsão pela Anvisa. ${ }^{15}$

Indo além, vejamos o enunciado n.l:

Nas demandas em tutela individual para internação de pacientes psiquiátricos e/ou com problemas de álcool, crack e outras drogas, quando deferida a obrigação de fazer contra o poder público para garantia de cuidado integral em saúde mental (de acordo com o laudo médico e/ou projeto terapêutico elaborado por profissionais de saúde mental do SUS), não é recomendável a determinação a priori de internação psiquiátrica, tendo em vista inclusive o risco de institucionalização de pacientes por longos períodos. (Conselho Nacional de Justiça, 2014) 
Quando se defere a obrigação de se garantir o "cuidado integral em saúde mental" de uma pessoa, isso ocorre de "acordo com laudo médico e/ou projeto terapêutico elaborado por profissionais de saúde mental do SUS". O mais interessante, pode ser a afirmação de que "não é recomendável a determinação a priori de internação psiquiátrica", trazendo nesse enunciado claramente uma visão de mundo aberta à desmedicalização e à desjudicialização.

Isso se choca com os pressupostos que embasam as ações do enunciado n.12 anteriormente citado. Enquanto este último postula uma consulta do juiz ao médico até porque versa sobre a prescrição de tratamento reduzida à prescrição medicamentosa, o enunciado n.l acaba por incluir outros "profissionais de saúde mental" como legitimados a emitir um parecer passível de ser acatado por um magistrado. São outros profissionais que prescrevem um tratamento. Isso reforça o caráter ambíguo e, por vezes, contraditório dos documentos analisados.

\section{Considerações finais}

A saúde é verdadeiramente um direito multifacetado, na medida em que comporta critérios sociais, políticos, jurídicos e, até mesmo, psicológicos. A compreensão do que seria o direito à saúde permite a definição de estratégias específicas para a efetivação de cada dimensão desse direito. De fato, a saúde não se reduz à mera ausência de doença, pois envolve aspectos que se encontram relacionados ao bem-estar físico, mental e social. Isso traz um desafio ainda mais complexo para as instituições jurídicas, pois se torna fundamental promover uma visão desmedicalizada da saúde, que deve considerar o usuário enquanto ser humano inserido em um contexto social específico e com subjetividades singulares.

Nesse sentido, em meio a contradições e ambiguidades, os documentos do CNJ revelam o seu caráter fortemente medicalizante. Ao situar como saberes privilegiados para a decisão judicial o médico e o farmacêutico, o CNJ pode reduzir a importância do trabalho multiprofissional desenvolvido por psicólogos, assistentes sociais e fisioterapeutas. A reprodução de uma visão medicalizada da saúde também pode ocorrer pela sobrevalorização do saber médico e farmacêutico no processo decisório judicial. A pouca participação de outros profissionais da saúde no cotidiano da decisão pode ajudar a reproduzir a ideia de saúde como ausência de doença, e não como um complexo biopsicossocial.

A reprodução de uma visão médico-farmacêutica pelas instituições jurídicas pode também contribuir para uma visão restrita do problema por parte de magistrados. Em verdade, é fundamental o desenvolvimento de uma visão multiprofissional e interdisciplinar dos problemas de saúde, sob risco de forte reducionismo decisório. Adicione-se o fato de questões originariamente externas ao saber-poder biomédico, tais como a adoção e mudança de nome, serem traduzidas à luz desse saber pela categoria do biodireito.

$\mathrm{Na}$ medida em que o Judiciário se fortalece no Brasil e assume o protagonismo na efetivação do direito à saúde, estaria esse Poder necessariamente efetivando o SUS? O que se observa, na verdade, são desafios profundos na 
relação entre Estado, sociedade e instituições jurídicas no processo de efetivação do direito à saúde.

\section{Notas}

$1 \mathrm{Na}$ análise de Roseni Pinheiro et al. (2005, p.15-16), se observam avanços jurídicos expressivos em dois aspectos: "O primeiro diz respeito ao estabelecimento da relevância pública dos serviços de saúde vis-à-vis outras modalidades de oferta de bens sociais; o segundo se refere à institucionalização de um arcabouço jurídico-normativo com princípios doutrinários e operacionais (universalidade, descentralização, integralidade, equidade e participação na comunidade), mediante a promulgação da Lei Orgânica da Saúde n.8.080/90. Dessa forma, configurou-se uma definição jurídico-normativa e organizativa da política de saúde do Estado brasileiro - o SUS".

2 Um exemplo de estudo a respeito do protagonismo das instituições jurídicas na saúde, com foco privilegiado no Ministério Público, é promovido por Asensi (2010). Outros estudos de Asensi e Pinheiro (2015) têm evidenciado diversas experiências inovadoras de efetivação do direito à saúde pela via judicial.

3 Como se vê ao longo do tópico, o único enunciado que menciona a existência de “outros profissionais" é o enunciado n.l.

4 "A inefetividade do tratamento oferecido pelo SUS, no caso concreto, deve ser demonstrada por relatório médico que a indique e descreva as normas éticas, sanitárias, farmacológicas (princípio ativo segundo a Denominação Comum Brasileira) e que estabeleça o diagnóstico da doença (Classificação Internacional de Doenças), tratamento e periodicidade, medicamentos, doses e fazendo referência ainda sobre a situação do registro na ANVISA (Agência Nacional de Vigilância Sanitária)" (Conselho Nacional de Justiça, 2014).

5 “Na composição dos Núcleos de Assessoramento Técnico (NAT’s) será franqueada a participação de profissionais dos Serviços de Saúde dos Municípios" (Conselho Nacional de Justiça, 2014).

6 "Sempre que possível, as decisões liminares sobre saúde devem ser precedidas de notas de evidência científica emitidas por Núcleos de Apoio Técnico em Saúde - NATS" (Conselho Nacional de Justiça, 2014).

7 "Recomenda-se ao Juiz a obtenção de informações do Núcleo de Apoio Técnico ou Câmara Técnica e, na sua ausência, de outros serviços de atendimento especializado, tais como instituições universitárias, associações profissionais, etc." (Conselho Nacional de Justiça, 2014).

8 "As prescrições médicas devem consignar o tratamento necessário ou o medicamento indicado, contendo a sua Denominação Comum Brasileira (DCB) ou, na sua falta, a Denominação Comum Internacional (DCI), o seu princípio ativo, seguido, quando pertinente, do nome de referência da substância, posologia, modo de administração e período de tempo do tratamento e, em caso de prescrição diversa daquela expressamente informada por seu fabricante, a justificativa técnica" (Conselho Nacional de Justiça, 2014).

9 “É recomendável a designação de audiência para ouvir o médico ou o odontólogo assistente quando houver dúvida sobre a eficiência, a eficácia, a segurança e o custo efetividade da prescrição" (Conselho Nacional de Justiça, 2014). 
10 "As altas de internação hospitalar de paciente, inclusive de idosos e toxicômanos, independem de novo pronunciamento judicial, prevalecendo o critério técnico profissional do médico" (Conselho Nacional de Justiça, 2015).

11 "Nos processos judiciais, a caracterização da urgência/emergência requer relatório médico circunstanciado, com expressa menção do quadro clínico de risco imediato" (Conselho Nacional de Justiça, 2015).

12 Tomamos aqui o termo ambiguidade na acepção trabalhada por Robert Castel (1978), em seu estudo clássico $O$ psicanalismo, ou seja, como constituinte da psicanálise e do campo analítico em si mesmo.

13 "É admissível, no registro de nascimento de indivíduo gerado por reprodução assistida, a inclusão do nome de duas pessoas do mesmo sexo, como pais" (Conselho Nacional de Justiça, 2014).

14 "Quando comprovado o desejo de viver e ser aceito enquanto pessoa do sexo oposto, resultando numa incongruência entre a identidade determinada pela anatomia de nascimento e a identidade sentida, a cirurgia de transgenitalização é dispensável para a retificação de nome no registro civil" (Conselho Nacional de Justiça, 2014).

15 Para mantermos os objetivos iniciais deste trabalho, não discutiremos os fundamentos biomédicos do corpus teórico-prático que constitui a Anvisa e suas ações.

\section{Referências}

ASENSI, F. D. Judicialização ou juridicização? Physis Revista de Saúde Coletiva, Rio de Janeiro, v.20, n.1, p.33-55, 2010. Disponível em: <http://www.scielo.br/scielo. php?pid=S0103-73312010000100004\&script=sci_abstract\&tlng=pt >. Acesso em: 12 jun. 2017.

ASENSI, F.; PINHEIRO, R. Judicialização da saúde no Brasil. Brasília: CNJ, 2015

BARBOZA, H. H. Biodireito x Direito Sanitário. In: ASENSI, F. D.; PINHEIRO, R. (Org.) Direito Sanitário. Rio de Janeiro: Elsevier, 2012.

BRASIL - PRESIDÊNCIA DA REPÚBLICA. Constituição da República Federativa do Brasil de 1988. Disponivel em: <http://www.planalto.gov.br/ccivil_03/constituicao/ constituicaocompilado.htm>. Acesso em: 12 jul. 2017.

CAMARGO JUNIOR, K. R. Medicalização, farmacologização e imperialismo sanitário. Cadernos de Saúde Pública, Rio de Janeiro, v.29, n.5, p.844-6, 2013. Disponível em: <http://www.scielo.br/scielo.php?script=sci_arttext\&pid=S0102-311X2013000500002 >. Acesso em: 12 jun. 2017.

CASTEL, R. O psicanalismo. Rio de Janeiro: Graal, 1978.

CASTRO, M. V. M.; SANTOS, M. M. O poder normativo do Conselho Nacional de Justiça: análise da Ação Declaratória de Constitucionalidade n.12/DF. Revista Direito UNIFACS, Salvador, n.131, p.1-32, 2011. Disponível em: <http://www.revistas.unifacs.br/index.php/redu/article/view/1480/116l>. Acesso em: 22 mar. 2017.

CLARKE, A. E.; MAMO, L.; FISHMAN, J. R.; SHIM, J. K., FOSKET, J. R. Biomedicalization: technoscientific transformations of health, illness, and u.s. Biomedicine. American Sociological Review, Washington DC, v.68, n.2, p.161-94, 2003. Disponível 
em: <http://www.jstor.org/stable/1519765?seq=1\#page_scan_tab_contents>. Acesso em: 12 jun. 2017.

CONRAD, P. The medicalization of society: on the transformation of human conditions into treatable disorders. The Johns Hopkins University Press: Baltimore, 2007.

CONSELHO NACIONAL DE JUSTIÇA. I Jornada de Direito da Saúde. Enunciados aprovados na I Jornada de Direito da Saúde do Conselho Nacional de Justiça em 15 de maio de 2014 - São Paulo-SP, São Paulo, maio 2014. Disponível em: <http://www. cnj.jus.br/images/ENUNCIADOS_APROVADOS_NA_JORNADA_DE_DIREITO_DA_SAUDE_\%20PLENRIA_15_5_14_r.pdf>. Acesso em: 20 jul. 2017.

II Jornada de Direito da Saúde. Enunciados aprovados II Jornada de Direito da Saúde, São Paulo, maio 2015. Disponível em: <http://www.cnj.jus.br/files/conteudo/destaques/arquivo/2015/05/96b5b10aec7e5954fcc1978473e4cd80.pdf> . Acesso em: 20 jul. 2017.

Regimento Interno do CNJ. Resolução n.67, de 3 de março de 2009. Disponível em: <http://www.cnj.jus.br///images/atos_normativos/resolucao/resolucao_67_03032009_10072017160032.pdf>. Acesso em: 22 mar. 2018.

FOUCAULT, M. Microfísica do Poder. 13. ed. Rio de Janeiro: Edições Graal, 1998. v. 7.

GAUDENZI, P.; ORTEGA, F. O Estatuto da Medicalização e as Interpretações de Ivan Illich e Michel Foucault como Ferramentas Conceituais para o Estudo da Desmedicalização. Interface, v.16, n.40, p.21-34, 2012. Disponível em: <http://www.scielo.br/ pdf/icse/vl6n40/aop2112.pdf>. Acesso em: 15 jul. 2017.

ILLICH, Ivan. A Expropriação da Saúde: Nêmesis da Medicina. Rio de Janeiro: Nova Fronteira, 1975.

LOYOLA, M. A. Médicos e curandeiros. São Paulo: Difel, 1984.

MYSZCZUK, A. P.; MEIRELLES, J. M. L. de. Bioética, biodireito e interpretação (bio) constitucional. In: XVII CONGRESSO NACIONAL DO CONPEDI, 2008, Belo Horizonte. Anais... Belo Horizonte, nov. 2008. p.332-53.

NUNES, J. A. Saúde, direito à saúde e justiça sanitária. Revista Crítica de Ciências Sociais, Coimbra, v.87, p.143-69, 2009. Disponível em: <https://rccs.revues.org/1588>. Acesso em: 15 jul. 2017.

PINHEIRO, Roseni et al. Demanda em saúde e direito à saúde: liberdade ou necessidade? Algumas considerações sobre os nexos constituintes das práticas de integralidade. In: PINHEIRO, R.; MATTOS, R. A. de. (Org.) Construção social da demanda: direito à saúde, 53 trabalho em equipe, participação e espaços públicos. Rio de Janeiro: Cepesc, 2005.

SCHIOCCHET, T. Exercício de direitos sexuais e reprodutivos por adolescentes no contexto brasileiro: repensando os fundamentos privatistas de capacidade civil a partir dos direitos humanos. in: ASENSI, F. D.; PINHEIRO, R. (Org.) Direito Sanitário. Rio de Janeiro: Elsevier, 2012.

SOUZA, E. F. A. A.; LUZ, M. T. Bases socioculturais das práticas terapêuticas alternativas. História, Ciências, Saúde-Manguinhos, Rio de Janeiro, v.16, n.2, p.393-405, 2009. Disponível em: <http://www.scielo.br/scielo.php?pid=S0104$-59702009000200007 \&$ script=sci_abstract\&tlng=pt $>$. Acesso em: 15 jul. 2017. 
TESSER, C. D. Medicalização social (II): limites biomédicos e propostas para a clínica na atenção básica. Interface - Comunicação, Educação e Saúde, Botucatu, v.10, n.20, p.347-62, 2006. Disponível em: <http://www.scielo.br/scielo. php?pid=S1414-32832006000200006\&script=sci_abstract\&tlng=pt $>$. Acesso em: 15 jul. 2017.

TESSER, C. D.; POLI NETO, P.; CAMPOS, G. W. S. Acolhimento e (des) medicalização social: um desafio para as equipes de saúde da família. Ciênc. Saúde Coletiva, Rio de Janeiro, v.15, supl.3, p.3615-24. 2010. Disponível em: <http://www.scielo.br/scielo. php?script=sci_arttext\&pid=S1413-81232010000900036>. Acesso em: 20 jul. 2017.

ZORZANELLI, R.; ORTEGA, F.; BEZERRA, B. Um panorama sobre as variações em torno do conceito de medicalização entre 1950-2010. Ciência \& Saúde Coletiva, v.19, n.6, p.1859-68, 2014. Disponível em: <http://www.scielo.br/scielo.php?script=sci_ar ttext\&pid=S1413-81232014000601859>. Acesso em: 20 jul. 2017.

RESUMO - A judicialização da saúde no Brasil desenvolve-se a partir de medicamentos, tratamentos, exames etc., envolvendo profissionais do direito para efetivar o direito à saúde, mobilizando saberes e práticas plurais e contraditórias, que reforçam a medicalização. Sendo assim, o artigo aborda a relação entre judicialização e medicalização na saúde. O objetivo do trabalho consiste em evidenciar, em análise documental, os parâmetros decisórios que o Poder Judiciário tem constituído desde 2010 a partir do Conselho Nacional de Justiça. Como resultado, observa-se que, ao situar como saberes privilegiados para a decisão judicial o médico e o farmacêutico, o CNJ reduz a importância do trabalho multiprofissional, ainda estimulando o tratamento de questões sociais e individuais, como a questão da opção sexual, à luz do "biodireito".

PALAVRAS-CHAVE: Judicialização da saúde, Medicalização, Opção sexual, Direito à saúde ABSTRACT - The judicialization of health in Brazil stems from medications, treatments, tests etc. requiring professionals of Law to effect the right to healthcare, mobilizing plural and contradictory knowledge and practices, which reinforce medicalization. Thus, this article addresses the relationship between judicialization and medicalization in healthcare. The objective of the paper is to show, by documental analysis, the decision-making parameters that the Judiciary has been establishing since 2010 through the National Council of Justice (CNJ). As a result, the CNJ reduces the importance of multiprofessional work while stimulating the treatment of social and individual issues (e.g., the issue of sexual choice) through the category of "biolaw".

KEYWORDS: Judicialization of health, Medicalization, Sexual identity, Right to healthcare.

Aline Marques é doutoranda em Saúde Coletiva - Instituto de Medicina Social/Universidade do Estado do Rio de Janeiro, membro do Laboratório de Pesquisa Sobre Práticas de Integralidade em Saúde. @ - alinemrqs13@gmail.com. / https://orcid.org/0000-0002-8434-4809.

Carlos Rocha é psicólogo, doutorando em Saúde Coletiva - Instituto de Medicina Social/Universidade do Estado do Rio de Janeiro. @ - carlos.efr@gmail.com / https://orcid.org/0000-0002-9879-0463. 
Felipe Asensi é mestre pelo Instituto Universitário de Pesquisas do Rio de Janeiro e doutor em Sociologia pelo Instituto de Estudos Sociais e Políticos/Universidade do Estado do Rio de Janeiro e pós-doutor em direito pela Universidade do Estado do Rio de Janeiro (UERJ). Professor adjunto da Universidade do Estado do Rio de Janeiro . @ - felipedml@yahoo.com.br / https://orcid.org/0000-0002-7522-7926.

Diego Machado Monnerat é mestre em direito pelo Programa de Pós-Graduação em direito da Universidade Católica e Petrópolis, advogado e professor-tutor da Universidade Unyleya. @- monneratdm@gmail.com

https://orcid.org/0000-0002-4016-5737.

Recebido em 24.11.2017 e aceito em 17.3.2018.

I e II Instituto de Medicina Social, Universidade do Estado do Rio de Janeiro, Rio de Janeiro, Brasil.

III Universidade do Estado do Rio de Janeiro, Rio de Janeiro, Brasil.

IV Universidade Unyleya, Rio de Janeiro, Rio de Janeiro, Brasil. 
